\title{
ON $\log$ MAJORIZATIONS FOR POSITIVE SEMIDEFINITE MATRICES
}

\author{
C.-S. LIN AND Y. J. CHO
}

Abstract. In this paper, we show that every log majorization for positive semidefinite matrices can be expressed in countable sets of log majorizations and all of them are equivalent to one another.

Mathematics subject classification (2010): 47A63.

Keywords and phrases: Log majorization for positive semidefinte matrices, $\beta$-power-mean, $\alpha$-powermean, Furuta's inequality, Furuta-type operator inequality.

\section{REFERENCES}

[1] T. Ando And F. HiaI, Log majorization and complementary Golden-Thomson type inequalities, Linear Algebra Appl. 197 (198) (1994), 113-131.

[2] R. Bhatia, Positive Definite Matrices, Princeton Press, 2007.

[3] T. FURUTA, $A \geqslant B \geqslant O$ assures $\left(B^{r} A^{p} B^{r}\right)^{1 / q} \geqslant B^{(p+2 r) / q}$ for $r \geqslant 0, p \geqslant 0, q \geqslant 1$ with $(1+2 r) q \geqslant$ $p+2 r$, Proc. Amer. Math. Soc. 101 (1987), 85-88.

[4] T. FurUtA, An extension of the Furuta inequality and Ando-Hiai log majorization, Linear Algebra Appl. 219 (1995), 139-155.

[5] T. FuRUTA, Invitation to Linear Operators, ISBN: 0-415-26799-4, Taylor \& Francis, 2001.

[6] T. FURUTA, Further extension of an order preserving operator inequality, J. Math. Inequal. 2 (2008), $465-472$.

[7] T. FURUTA, Log majorization via an order preserving operator inequality, Linear Algebra Appl. 431 (2009), 132-138.

[8] T. FURUTA, An extension of order preserving operator inequality, Math. Inequal. Appl. 13 (2010), $49-56$.

[9] F. Kubo And T. Ando, Means of positive linear operators, Math. Ann. 246 (1980), 205-224.

[10] C.-S. Lin, On operator inequalities in terms of geometric mean, Internat. J. Pure Appl. Math. 58 (2010), 299-308.

[11] C.-S. Lin, Generalization of $\beta$-power-mean for operators, Internat. J. Pure Appl. Math. 62 (2010), 275-285.

[12] C.-S. Lin, On countable sets of order preserving operator inequalities in Hilbert spaces, Internat. J. Pure Appl. Math. 68 (2011), 189-199.

[13] C.-S. Lin AND Y. J. CHO, Characterizations of operator inequality $A \geqslant B \geqslant C$, Math. Inequal. Appl. 14 (2011), 575-580. 